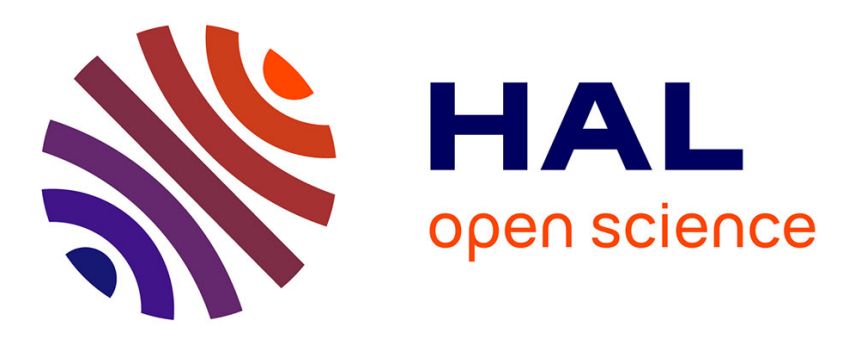

\title{
Dispersal polymorphism in an invasive forest pest affects its ability to establish
}

Christelle Robinet, Andrew Liebhold

\section{To cite this version:}

Christelle Robinet, Andrew Liebhold. Dispersal polymorphism in an invasive forest pest affects its ability to establish. Ecological Applications, 2009, 19 (7), pp.1935-1943. 10.1890/08-1971.1. hal02657867

\section{HAL Id: hal-02657867 \\ https://hal.inrae.fr/hal-02657867}

Submitted on 30 May 2020

HAL is a multi-disciplinary open access archive for the deposit and dissemination of scientific research documents, whether they are published or not. The documents may come from teaching and research institutions in France or abroad, or from public or private research centers.
L'archive ouverte pluridisciplinaire HAL, est destinée au dépôt et à la diffusion de documents scientifiques de niveau recherche, publiés ou non, émanant des établissements d'enseignement et de recherche français ou étrangers, des laboratoires publics ou privés. 
Version définitive du manuscrit publié dans / Final version of the manuscript published in :

Ecological Applications. 2009, 19(7), 1935-1943

\section{Dispersal polymorphism in an invasive forest pest affects its ability to establish}

Christelle Robinet ${ }^{1,2}$ and Andrew M. Liebhold ${ }^{2}$

${ }^{1}$ INRA, UR 633 Zoologie Forestière, F-45075 Orléans, France

${ }^{2}$ U.S. Forest Service Northern Research Station, 180 Canfield Street, Morgantown, West Virginia 26505, USA

* Corresponding author: Christelle Robinet, robinet@orleans.inra.fr ;

Tel.: +33.2.38.41.78.00; Fax: +33.2.38.41.78.79; present address:

INRA, Zoologie Forestière, 2163 Avenue de la Pomme de Pin, CS 40001 Ardon, 45075 Orléans Cedex 2, France

Running heading: "Dispersal could prevent invasion” 


\section{Summary}

Given the increasing number of biological invasions, there is a crucial need to identify life-history traits that promote invasion. Invasiveness reflects capabilities for both establishment after introduction, and spread following establishment. In this paper, we explore, via simulation, the interacting effects of dispersal and Allee effects on both invasion processes. Dispersal capability is a trait that has been widely recognized to facilitate invasions. However, dispersal dilutes local population densities in isolated populations and this could strengthen Allee effects, ultimately promoting extinction of invading populations.

A spatially explicit, stochastic individual-based model was used to simulate dispersal, mating and growth in isolated, newly arrived invading populations. We used the invasion of North America by the gypsy moth, Lymantria dispar, as a case study because: (a) a great amount of biological data on the species is available; (b) Allee effects caused by mate location failure are known to play an important role in its establishment and spread; (c) a dispersal polymorphism has previously been identified: in some populations adult females are fully capable of flight but in other populations females are not flight capable. We considered that a hypothetical number of eggs were introduced at a single location, originating from populations with varying female dispersal capabilities, and then used simulation models to evaluate the population growth rate over two generations as well as spread distance.

Non-dispersing populations had the highest growth rates and inclusion of even limited dispersal capabilities caused population growth rates to be greatly diminished. The Allee threshold was 700 eggs for non-dispersing populations and 1400 eggs for the long-distance dispersing populations. Thus, for an intermediate number of eggs initially introduced, non-dispersing populations would most likely establish whereas dispersing populations would likely become extinct. 
Spread distance increased linearly with the number of eggs initially introduced in both dispersing and non-dispersing populations, but rapidly reached a limit for non-dispersing populations.

Though species capable of long-distance dispersal may invade a larger area than nondispersing species, their growth rates are likely to be considerably lower and eradication should be easier. Following these results, strategies for managing invasions should be adjusted for the interactions between Allee effects and dispersal.

\section{Key-words}

Allee effects; Biological invasion; Diffusion; Dispersal; Gypsy moth; Individual-based model; Lymantria dispar; Mating success; Stochasticity. 


\section{INTRODUCTION}

Increasing levels of world trade have lead to elevated rates of invasions by non-indigenous species around the globe (Levine and D’Antonio 2003, McCullough et al. 2006). However, only a small fraction of arriving individuals are able to survive and found new populations (Williamson and Fitter 1996) and only a small fraction of these established species have noticeable effects on invaded ecosystems (Mack et al. 2000, Levine et al. 2003). Nevertheless, a small but important fraction of these biological invasions exhibit dramatic ecological and economic impacts in the newly invaded environment (Pimentel et al. 2000, 2005). A critical activity for understanding and solving the invasive species problem is the prediction of which species are likely to be successful invaders (Kolar and Lodge 2001, Hayes and Barry 2008).

When evaluating the potential invasiveness of a species, it is important to consider the suitability of the area (e.g., presence of favorable habitat), but also life history traits relative to all invasion phases (arrival, establishment and spread) (Kolar and Lodge 2002). Substantial effort has focused on identifying life history traits that lead certain species to be particularly prone to become associated with specific invasion pathways (e.g., Andersen et al. 2004, Kenis et al. 2007). It has also been recognized that invasion spread is likely to be greater for more mobile species. However, less attention has focused on species characteristics that increase the probability of establishment.

There is growing recognition that population establishment is strongly influenced by Allee effects which refers to decreasing per capita growth with decreasing density (Drake 2004, Taylor and Hastings 2005, Drake and Lodge 2006, Courchamp et al. 2008). Allee effects may arise in lowdensities as a result of various mechanisms such as failure to find mates, inability to satiate predators and failure to overcome host defenses (Allee et al. 1949, Courchamp et al. 1999, 2008, Stephens and Sutherland 1999, Taylor and Hastings 2005). In many situations, Allee effects may cause newly arrived populations to decline toward extinction. Consequently, life history traits that contribute to Allee effects may be of critical importance in determining invasion success. 
Here we explore how a life history trait (female dispersal) interacts with a component of reproduction process (mate-finding) to affect a demographic Allee effect and establishment. There is some information on how mate searching behavior (Wells et al. 1998, Berec and Boukal 2004) and sex determination mechanisms (Berec et al. 2001) affect the strength of Allee dynamics. Other studies have shown that temporal asynchrony in male and female sexual maturation can also intensify Allee effects due to mate-location failure and consequently promote extinction of invading populations (Calabrese and Fagan 2004, Robinet et al. 2007). Theoretical studies suggest that dispersal may also intensify Allee effects due to mate location failure because it results in greater dispersion of adults, thereby reducing the probability that mates will locate each other (Hopper and Roush 1993, South and Kenward 2001, Jonsen et al. 2007). The concept that dispersal as a trait detracts from a species' invasion capabilities has not been explored in any specific invasion systems and runs counter to other conclusions that dispersal promotes invasion success (Ehrlich 1989, Lodge 1993, Schöpf and Sih 2004). Furthermore, eradication has previously been considered to be generally less successful when the targeted species spreads quickly (Hulme 2006). Therefore, in this study we perform an in-depth exploration, using the gypsy moth as a model system, of how dispersal capabilities affect Allee effects and consequently affect the establishment of invading populations.

The gypsy moth is an ideal system for studying how dispersal capabilities affect mating success and invasion success, in part, because considerable information already exists about the demographics of populations invading North America. In particular, analyses of time series from invading populations provide ample evidence of a strong demographic Allee effect that causes the extinction of low-density isolated populations (Liebhold and Bascompte 2003, Whitmire and Tobin 2006, Tobin et al. 2007). In addition, there is good evidence that mate location failure produces a dominant component Allee effect and ultimately contributes to a demographic Allee effect (Sharov et al. 1995, Robinet et al. 2007, 2008, Tobin et al. 2009). 
The gypsy moth was accidentally introduced in 1868-1869 from France to North America near Boston and subsequently has slowly spread over a large portion of eastern North America. The slow rate by which this species has spread in North America can be largely attributed to a lack of mobility; females in these invading populations are flightless. However, through out the gypsy moth's extensive native range in Europe, North Africa and Asia, there is considerable variability in female flight capabilities. While flight is completely absent in most European populations, other populations exhibit limited flight and virtually all Asian populations exhibit at least some female flight capabilities (Mikkola 1971, Schaefer et al. 1984, Baranchikov 1989, Ponomarev 1994, Koshio 1996, Keena et al. 2008, Liebhold et al. 2008). Since the early 1990s there have been several instances in which populations with flight-capable females were accidentally introduced to North America (Bogdanowicz et al. 1993). Because of the perception that populations with flightcapable females would be much more difficult to eradicate, the U.S. Department of Agriculture has adopted an approach to eradicating populations of Asian origin that is much more aggressive than what is applied to populations of European origin. Several of the efforts to eradicate Asian gypsy moth invasions in the USA and Canada have involved spraying microbial pesticides over large areas, costing millions of dollars (Wallner 1996). However, if dispersal strengthens Allee effects, as has been earlier suggested in generalized models (Hopper and Roush 1993), then populations with flight-capable females may actually be easier to eradicate than populations with more limited dispersal capabilities (Hulme 2006). Consequently, we explore here, using a stochastic, individualbased model, the effect of the female flight trait on mating success, Allee effects and invasion success.

We assembled demographic information in an individual-based stochastic simulation model to determine the effects of adult female dispersal on the probability of gypsy moth establishment. This model was derived from Robinet et al. (2008), which simulated the spatial dynamics of isolated populations (with flightless females) following transport of a given number of egg masses to a point location. However, in the current model we considered that, once mated, females could 
disperse and lay an egg mass at varying distances. The most important result from these simulations is that the growth rate (and probability of establishment) of the flying morph is considerably lower than for the flightless morph. As a result, eradication of populations with flying females may actually be more easily accomplished than for populations with flightless females (the historically invasive morph). 


\section{METHODS}

\section{Formulation of the model}

Simulations performed here were based on a model modified from the individual-based model described by Robinet et al. (2008) (Fig. 1). In the current model, we assumed that a total of $N_{\text {egg }}$ eggs were initially introduced at a given point, isolated from the source population, and that female fecundity was then equal to $f$. Gypsy moth fecundity is strongly density dependent (Campbell 1978); since the founding population will initially be at low density, we can assume that fecundity will be then relatively high (around 500 eggs per female).

The original model by Robinet et al. (2008) designated the spatial location of individuals into individual cells in a grid, but in our model, we assigned the precise location of each individual in continuous space with no boundaries. This modification allowed us to consider any magnitude of dispersal without computer memory constraints. We applied the same successive stochastic processes as in Robinet et al. (2008): (1) larval dispersal, using a diffusion model with a diffusion coefficient of $0.003 \mathrm{~km}^{2}$ per generation (Shigesada and Kawasaki 1997, Liebhold and Tobin 2006); (2) larval / pupal mortality, with a mortality probability of 95\%; (3) adult emergence, using a Gaussian temporal distribution with a standard deviation of 10 days and an offset of 5 days between peak male and female emergence (Robinet et al. 2007); (4) mate finding, using a non-linear regression model, previously fit to experimental data, that predicts the probability that a given male will find a given female for a given temporal and spatial offset between the male and female; (5) mating, with a probability of 0.91 that mating will occur once the male has found the female (Charlton and Cardé 1990). This model tracked each individual from the egg introduction to mating success. Note that the non-linear regression model for mate-finding (4) was originally fit to data from populations with non-dispersing females. Here we assumed that mate finding was similar in populations both with and without dispersing females because, in all types of gypsy moth 
populations, mate-location proceeds by males searching out females via female-released pheromones (even in populations with flying females) and the searching ability of males can reasonably be assumed to be identical among all populations.

Here, we extend the basic model of Robinet et al. (2008) by considering that, once mated, females may disperse. Furthermore, we simulated populations, using the same stochastic processes, over an additional generation and then calculated mating success in the second generation. We did not extend simulations over a larger number of generations because of computational limitations. As a result, we considered the following additional processes: (6) post-mating female dispersal was simulated via a diffusion model parameterized with a specific diffusion coefficient $D$. We assumed that females laid a single egg-mass (composed of $f$ eggs with a 1:1 sex-ratio) at the location to which they dispersed, and then we applied processes (1)-(5) for the second generation. The 2-year population growth rate was calculated as the total number of eggs laid by all females at the end of the second generation divided by $N_{\text {egg }}$, the number of eggs originally introduced at the beginning of the first generation. Hereafter, we refer to dispersing and non-dispersing populations to describe the dispersal capabilities of female adults rather than $1^{\text {st }}$ instar larvae since these larvae always disperse (though over shorter distances).

The partial differential equation related to the diffusion model was originally solved (Robinet et al. 2008). Here, we instead directly used the Gaussian probability distribution (of variance $2 D t$, Kareiva 1983) corresponding to the diffusion model of steps (1) and (6):

$$
p(x, y, t)=\frac{1}{4 \pi D t} \exp \left(-\frac{x^{2}+y^{2}}{4 D t}\right)
$$

Thus, for each dispersing individual, we generated a random distance $r$ with a mean $=0$ and a standard deviation $=\sqrt{2 D}$, and a random direction $\theta$.

\section{Simulations}


To evaluate the effects of female dispersal on Allee effects, we calculated the 2-year growth rate (defined as the number of eggs laid by females of the second generation divided by the number of eggs initially introduced) for various values of the diffusion coefficient for adult female dispersal ( $D=0$ to $2 \mathrm{~km}^{2}$ per generation by increments of 0.1 ) and various numbers of eggs initially introduced ( $N_{\text {egg }}=100$ to 3000 by increments of 100 ). To more easily interpret this surface plot, we considered that $N_{\text {egg }}=500,1000$ or 3000 eggs were initially introduced at a single point, and plotted the growth rate with increasing values of the diffusion coefficient. We also calculated the 2-year growth rate with increasing values of $N_{\text {egg }}$ for $D=0$ and $D=1 \mathrm{~km}^{2}$ per generation representing respectively non-dispersing and long-distance dispersing populations. We calculated the mean and 95\% confidence interval of the growth rate in both cases.

To complete our comparative analysis, we also calculated the distance spread by invading populations of each dispersal morph. First the number of mated females present in each $1 \mathrm{~km} \times 1$ $\mathrm{km}$ cell in a grid overlaid at the end of the second generation was calculated and the occupancy area was calculated as the number of non-zero cells. The spread distance was calculated as the square root of the occupancy area. We made simulations for each value of $N_{\text {egg }}$ from 100 to 3000 by increments of 100, and each $D$ from 0 to $2 \mathrm{~km}^{2}$ per generation by increments of 0.1 . To more easily interpret the results, we also calculated the spread distance for increasing values of $D$, assuming $N_{\text {egg }}=500,1000$ and 3000 eggs. Reciprocally, we calculated the spread distance for increasing number of eggs $N_{\text {egg }}$, using both $D=0$ and $D=1$. We calculated the mean and $95 \%$ confidence interval of the spread distance in both cases.

We assumed that females had a fecundity of $f=500$ eggs and we made 500 replicate simulations for each combination of $D$ and $N_{\text {egg }}$. All of these simulations were performed in R (R Development Core Team 2007); code is provided in online appendix S1.

\section{RESULTS}


Simulated growth rates declined rapidly with increasing levels of the diffusion coefficient, even for small $D$ values (Figs. 2ab). Above a threshold level of female dispersal, the growth rate seemed to converge toward a limit (Fig. 2b). Beyond this threshold, egg-masses that initialized the second generation were spread so widely that they behaved like independent egg-mass introductions. Consequently, growth rates and establishment probabilities were greatly reduced for dispersing populations. Furthermore, the growth rate limit increased with the number of eggs initially introduced because there were many more independent egg-masses. Figures 2a,b also illustrate the effect of the initial population size, $N_{\text {egg }}$, on growth rates. Simulated population growth was typical of an Allee effect; as the population size increased, so did the Allee threshold. Also, as the initial population size increased, the probability that isolated populations might interact increased and this caused the Allee threshold to increase with increasing diffusion coefficient. The standard deviation of the growth rate was relatively low $($ mean $=1.14$, median $=0.91)$.

Simulation of population growth rates with increasing numbers of eggs initially introduced, indicated very different behaviors depending on the presence of long-distance dispersal (Figs. 2ac). Growth rates in populations capable of long-distance dispersal increased slowly and almost linearly with the number of eggs initially introduced, whereas growth rates for non-dispersing populations increased faster, and crossed the threshold, $r=1$, much earlier. The Allee threshold (below which populations are likely to go extinct) of the non-dispersing population was ca. 700 eggs and, ca. 1400 eggs for the long-distance dispersing population. If an intermediate number of eggs was introduced (e.g., 1000 eggs), the population would probably establish if female dispersal was absent but it would likely go extinct if females were capable of long-distance dispersal.

In some simulations, spread distances were also affected by female dispersal capabilities (Fig. 3a). For populations initialized at $N_{\text {egg }}=500$ and 1000 eggs, spread distances were not substantially affected by long distance dispersal (Fig. 3b). The dispersing population could not expand faster because of strong Allee effects. However, for the largest initial population size tested, $N_{\text {egg }}=3000$, spread distance was higher and increased with diffusion coefficient. This relationship 
is clearly seen in Fig. 3c: the increase in spread distance with the number of eggs initially introduced was nearly identical for both dispersing and non-dispersing morphs as long as $N_{e g g}<$ 1000. However for higher ranges of the initial number of eggs $\left(N_{\text {egg }}>1000\right)$, spread distance differed considerably between the dispersing and non-dispersing populations; in dispersing populations, spread distance continuously increased with initial population size, but in nondispersing populations, spread distance leveled off to a constant value of about $1 \mathrm{~km}$. The standard deviation of spread distance was relatively low $($ mean $=1.18$, median $=1.21)$.

\section{DISCUSSION}

The results described here indicate that post-mating dispersal and Allee effects, caused by matefinding failure, interact in their effects on invasion success in the gypsy moth. Specifically, it appears that in populations capable of long-distance dispersal (by females), establishment is diminished because females disperse and oviposit at sites that are so distantly located from each other that males from different egg masses are not exchanged among colonies. Previous studies (Robinet et al. 2007, 2008) indicate that progeny from a single, isolated gypsy moth egg mass are usually so sparse that they are unable to locate mates and consequently mostly go extinct. In populations with dispersing adult females, egg masses that start the second generation following introduction are so widely dispersed that they effectively represent independent isolated introductions that usually do not persist. However, in populations where female flight is lacking, the egg masses that start the second generation will be more closely packed, creating a locally elevated density of males that increases the chances of females mating and the persistence of population.

Unfortunately empirical data comparing the persistence of isolated flight-capable gypsy moth populations with isolated populations possessing flightless females are lacking; thus we are unable to confirm the important prediction from our model that flight-capable populations are more 
extinction prone. However, it is possible to generalize that while flightless populations have a proven track record as successful invaders, successful invasion establishment by populations with flight-capable females has never been confirmed anywhere in the world. There are many records of ships, containers, etc. that are contaminated with large numbers of gypsy moth egg masses emanating from Asian locations, and likely there are many more such arrivals that have gone unnoticed. The fact that none of these Asian populations have established to the point that they are detected in trapping grids suggests that they may, indeed, be less likely to establish.

Based upon simple reaction-diffusion principles, we may expect that invading populations with greater dispersal capabilities will spread more quickly across the habitat (Shigesada and Kawaski 1997). However, the presence of an Allee effect is known to substantially diminish spread rates (Lewis and Kareiva 1993, Taylor and Hastings 2005). In our simulations we found that when the size of the colonizing population size was small, that spread distance was largely unaffected by dispersal capabilities and only increased when initial population size was large (Fig. 3c). These results again appear to reflect the interaction between post-mating dispersal and Allee effects. Invasiveness reflects both the ability of an invading population to establish after arrival, as well as its ability to spread. In this paper, we have explored the impact of Allee effects on both processes. Extensive dispersal capabilities have generally been considered a trait promoting invasion success (Ehrlich 1989, Lodge 1993, Schöpf and Sih 2004). Moreover, dispersing populations can generally invade more successfully fragmented habitats than low-dispersing populations (With 2002). However, here we demonstrate contrasting effects of dispersal on invasion success in homogeneous habitat. Even though stronger dispersal potentially increases the rate of spread by an invader (Fig. 3), it also substantially reduces the growth rate of the newlyfounded population and consequently increases the probability of establishment failure (Fig. 2).

This antagonist effect is particularly important in terms of invasion management. For example in the case of gypsy moth, a newly arrived flight-capable morph may spread faster than a flightless population once it is established, but the probability of establishment is far lower. 
Because the Allee threshold is much higher in flight capable populations, populations colonized initially by a small number of invaders are likely to go extinct without intervention. In the case of larger populations, a small fraction needs to be killed in order to eradicate the population (Liebhold and Tobin 2008). The conclusion that flight capable populations are easier to eradicate is in contradiction to the current U.S. Dept. of Agriculture policy that directs more rapid and intensive treatment for eradicating flight capable populations. The results presented here therefore suggest a need to reconsider strategies for eradicating Asian strains of the gypsy moth in the U.S., as well as in other countries, such as New Zealand (Ross 2005).

The model used here assumed some important simplifications that should be considered. One possibility that may modify our results is that flying females may aggregate and concentrate egg masses in select locations. For example, gypsy moth females are known to aggregate on rocks and other objects (Charlton et al. 1999). In this case, aggregation would counterbalance the dispersal effect: the growth rate would be considerably higher and Allee effects may be similar to those of the flightless morph. However, aggregation by females is also likely to reduce spread rates. Thus, in the case of aggregation by flying females, then populations could be eradicated by adopting a similar strategy applied to flightless populations. Another consideration is that in our simulations of gypsy moth dynamics, we assumed that all adult female dispersal occurred after mating (Charlton et al. 1999). However, pre-ovipositional flight has also been observed in some Asian populations (Koshio 1996). We anticipate that pre-ovipositional flight would cause males and females to be separated by even greater distances, thereby increasing the probability of matelocation failure and consequently, cause decreased population growth and reduce the probability of establishment.

In our model, we combined two dispersal functions: a Gaussian curve to describe shortdistance dispersal of larvae, and another Gaussian curve to describe dispersal capability of female adults. Consequently, this model could be considered to be a type of stratified dispersal model (Shigesada and Kawasaki 1997). Allee effects are known to particularly affect the spread of 
populations exhibiting stratified dispersal (Hui and Li 2004, Taylor et al. 2004). Spread into adjoining areas can only proceed when the size of the donor population is large enough to provide a number of emigrants sufficient to exceed the Allee threshold, allowing establishment of isolated colonies (Hui and Li 2004). This process is at the origin of pulse invasion waves of gypsy moth spread, observed in North America (Johnson et al. 2006). Our results suggest that below ca. 1000 eggs initially introduced, non-dispersing and dispersing morphs expand at the same rate. In contrast, above this threshold, non-dispersing morph cannot expand further whereas the dispersing morph continues its expansion (Fig. 3c).

Heritability of female gypsy moth flight capability has recently been investigated (Keena et al. 2001, 2007). Though alleles for flight capability were not originally present in the North American populations, addition of flight-capable individuals via new introductions could result in some flight capability in hybrids and accelerate spread in North America (Keena et al. 2007). Unfortunately no information is available that would allow us to predict selection for flight and the long-term persistence of alleles for flight in gypsy moth populations. Indeed, the ultimate evolutionary reason why females in some populations are flight capable but others are not is unknown.

Insect flight capability is a genetic feature that is shaped through evolution by a variety of selective forces (Zera and Denno 1997). Flightless populations might have encountered particularly high Allee effects during population bottlenecks and this may have resulted in selection for reduced dispersion. Indeed the phenomenon of loss of flight by adult females has evolved independently many times in the Lepidoptera (Wagner and Liebherr 1992). Several hypotheses have been proposed to explain this phenomenon (Barbosa et al. 1989) but the concept that flightlessness is an adaptation that allows isolated populations to persist at low densities has not been considered and deserves more attention.

The results presented in this paper could be extended to other animal or plant species for assessing the risk of biological invasion. Risk analyses should consider the effects of dispersal on 
establishment and spread (Williamson 2006). In considering the extent to which dispersal affects invasiveness, interactions with Allee effects should be considered also. Variability among species in life history traits causes considerable variability among species in the strength of Allee effects (Courchamp et al. 1999, 2008). Thus, we can expect that there may be substantial variation among species in the extent to which dispersal has a deleterious effect on establishment and this would be reflected in their invasiveness.

\section{ACKNOWLEDGEMENTS}

We thank Ottar Bjørnstad for his insightful suggestions about dispersal modeling.

\section{REFERENCES}

Allee, W. C., A. E. Emerson, O. Park, T. Park, and K. P. Schmidt. 1949. Principles of Animal Ecology. W. B. Saunders, Philadelphia, PA.

Andersen, M. C., H. Adams, B. Hope, and M. Powell. 2004. Risk Analysis for Invasive Species: General Framework and Research Needs. Risk Analysis 24: 893-900.

Baranchikov, Y. N. 1989. Ecological basis of the evolution of host relationships in Eurasian gypsy moth populations, pp. 319-338. In W. E. Wallner and K. A. McManus [Tech. Coord.], Proceedings, Lymantriidae: A Comparison of Features of New and Old World Tussock Moths, USDA Gen. Tech. Rep. NE-123. Broomall, PA.

Barbosa, P., V. Krischik, and D. Lance. 1989. Life-history traits of forest-inhabiting flightless Lepidoptera. American Midland Naturalist 122: 262-274.

Berec, L., and D. S. Boukal. 2004. Implications of mate search, mate choice and divorce rate for population dynamics of sexually reproducing species. Oikos 104: 122-132. 
Berec, L., D. S. Boukal, and M. Berec. 2001. Linking the Allee effect, sexual reproduction, and temperature-dependent sex determination via spatial dynamics. The American Naturalist 157: 217-230.

Bogdanowicz, S. M., W. E. Wallner, J. Bell, T. M. Odell, and R.G. Harrison. 1993. Asian gypsy moths (Lepidoptera: Lymantriidae) in North America: evidence from molecular data. Annals of the Entomological Society of America 86: 710-715.

Calabrese, J. M., and W. F. Fagan. 2004. Lost in time, and single: reproductive asynchrony and the Allee effect. The American Naturalist 164: 25-37.

Campbell, R. W. 1978. Some effects of gypsy moth density on rate of development, pupation time, and fecundity. Annals of the Entomological Society of America 71: 442-448.

Charlton, R. E., and R. T. Cardé. 1990. Orientation of Male Gypsy Moths, Lymantria Dispar (L.), to Pheromone Sources: The Role of Olfactory and Visual Cues. Journal of Insect Behavior 3: 443-469.

Charlton , R. E. , R. T. Cardé, and W. E. Wallner. 1999. Synchronous crepuscular flight of female Asian gypsy moths: relationships of light intensity and ambient and body temperatures. Journal of Insect Behavior 12: 517-531.

Courchamp, F., T. Clutton-Brock, and B. Grenfell. 1999. Inverse density dependence and the Allee effect. Trends in Ecology \& Evolution 14: 405-410.

Courchamp, F., L. Berec, and J. Gascoigne. 2008. Allee effects in ecology and conservation. Oxford University Press.

Drake, J. M. 2004. Allee effects and the risk of biological invasion. Risk Analysis 24: 795-802.

Drake, J. M., and D. M. Lodge. 2006. Allee effects, propagule pressure and the probability of establishment: risk analysis for biological invasions. Biological Invasions 8: 365-375.

Ehrlich, P. R. 1989. Attributes of invaders and the invading processes: vertebrates. In: Biological invasions: a global perspective (Drake, J.A. et al., eds), pp. 315-328, Wiley. 
Hayes, K. R., and S. C., Barry. 2008. Are there any consistent predictors of invasion success? Biological Invasions 10: 483-506.

Hopper, K. R., and R. T. Roush. 1993. Mate finding, dispersal, number released, and the success of biological control introductions. Ecological Entomology 18: 321-331.

Hui, C., and Z. Li. 2004. Distribution patterns of metapopulation determined by Allee effects. Population Ecology 46: 55-63.

Hulme, P. E. 2006. Beyond control: wider implications for the management of biological invasions. Journal of Applied Ecology 43: 835-847.

Johnson, D. M., A. M. Liebhold, P. C. Tobin, and O. N. Bjørnstad. 2006. Allee effects and pulsed invasion by the gypsy moth. Nature 444: 361-363.

Jonsen, I. D., R. S. Bourchier, and J. Roland. 2007. Influence of dispersal, stochasticity, and Allee effect on the persistence of weed biocontrol introductions. Ecological Modelling 203: 521-526.

Kareiva, P. M. 1983 Local movement in herbivorous insects: applying a passive diffusion model to mark-recapture field experiments. Oecologia 57: 322-327.

Keena, M. A., W. E. Wallner, P. S. Grinberg, and R. T. Cardé. 2001. Female flight propensity and capability in Lymantria dispar (Lepidoptera: Lymantriidae) from Russia, North America, and their reciprocal $F_{1}$ hybrids. Environmental Entomology 30: 380-387.

Keena, M. A., P. S. Grinberg, and W. E. Wallner. 2007. Inheritance of female flight in Lymantria dispar (Lepidoptera: Lymantriidae). Environmental Entomology 36: 484-494.

Keena, M. A., M.-J. Côté, P. S. Grinberg, and W. E. Wallner. 2008. World distribution of female flight and genetic variation in Lymantria dispar (Lepidoptera: Lymantriidae). Environmental Entomology 37: 636-649.

Kenis, M., W. Rabitsch, M.-A. Auger-Rozenberg, and A. Roques. 2007. How can alien species inventories and interception data help us prevent insect invasions? Bulletin of Entomological Research 97: 489-502. 
Kolar, C. S., and D. M. Lodge. 2001. Progress in invasion biology: predicting invaders. Trends in Ecology \& Evolution 16: 199-204.

Kolar, C. S., and D. M. Lodge. 2002. Ecological predictions and risk assessment for alien fishes in North America. Science 298: 1233-1236.

Koshio, C. 1996. Pre-ovipositional behaviour of female gypsy moth, Lymantria dispar L. (Lepidoptera: Lymantriidae). Applied Entomology and Zoology 31: 1-10.

Levine J. M., and C. M. D’Antonio. 2003. Forecasting biological invasions with increasing international trade. Conservation Biology 17: 322-326.

Levine, J. M., M. Vila, C. M. D'Antonio, J. S. Dukes, K. Grigulis, and S. Lavorel. 2003. Review Paper. Mechanisms Underlying the Impacts of Exotic Plant Invasions Proceedings Royal Society: Biological Sciences 270: 775-781.

Lewis, M. A., and P. Kareiva. 1993. Allee dynamics and the spread of invading organisms. Theoretical Population Biology 43: 141-58.

Liebhold, A., and J. Bascompte. 2003. The Allee effect, stochastic dynamics and the eradication of alien species. Ecology Letters 6: 133-140.

Liebhold, A. M., and P. C. Tobin. 2006. Growth of newly established alien populations: comparison of North American gypsy moth colonies with invasion theory. Population Ecology 48: 253-262.

Liebhold, A. M., and P. C. Tobin. 2008. Population ecology of insect invasions and their management. Annual Review of Entomology 53: 387-408.

Liebhold, A. M., N. Kamata, M. Turcáni. 2008. Inference of adult female dispersal from the distribution of gypsy moth egg masses in a Japanese City. Agricultural and Forest Entomology 10: 69-73.

Lodge, D. M. 1993. Biological Invasions: lessons for ecology. Trends in Ecology \& Evolution 8: 133-137. 
Mack, R. N., D. Simberloff, W. M. Lonsdale, H. Evans, M. Clout, and F. A. Bazzaz. 2000. Biotic invasions: causes epidemiology, global consequences and control. Ecological Applications 10: 689-710.

McCullough, D. G., T. T. Work, J. F. Cavey, A. M. Liebhold, and D. Marshall. 2006. Interceptions of nonindigenous plant pests at US ports of entry and border crossings over a 17-year period. Biological Invasions 8: 611-630.

Mikkola, K. 1971. The migratory habit of Lymantria dispar (Lep.: Lymantriidae) adults of continental Eurasia in the light of a flight to Finland. Acta Entomologica Fennica 28: 107-120.

Pimentel, D., L. Lach, R. Zuniga, and D. Morrison. 2000. Environmental and economic costs of nonindigenous species in the United States. BioScience 50: 53-65.

Pimentel, D., R. Zuniga, and D. Morrison. 2005. Update on the environmental and economic costs associated with alien-invasive species in the United States. Ecological Economics 52: 273-288.

Ponomarev, V. I. 1994. Population-genetic characteristics of outbreaks of mass propagation of gypsy moth (Lymantria dispar L.). Russian Journal of Ecology 25: 380-286.

R Development Core Team. 2007. R: A language and environment for statistical computing. R Foundation for Statistical Computing, Vienna, Austria. ISBN 3-900051-07-0, URL http://www.R-project.org .

Robinet, C., A. M. Liebhold, and D. Gray. 2007. Variation in developmental time affects mating success and Allee effects. Oikos 116: 1227-1237.

Robinet, C., D. R. Lance, K. W. Thorpe, K. S. Onufrieva, P. C. Tobin, and A. M. Liebhold. 2008. Dispersion in time and space affect mating success and Allee effects in invading gypsy moth populations. Journal of Animal Ecology 77: 966-973.

Ross , M. 2005. \$80 million pest eradicated . Biosecurity New Zealand 61: 18-19.

Schaefer, P. W., R. M. Weseloh, X. Sun, W. E. Wallner, and J. Yan. 1984. Gypsy moth, Lymantria (=Ocneria) dispar (L.) (Lepidoptera: Lymantriidae), in the People’s Republic of China.

Environmental Entomology 13: 1535-1541. 
Schöpf, R. J., and A. Sih. 2004. Dispersal behavior, boldness, and the link to invasiveness: a comparison of four Gambusia species. Biological Invasions 6: 379-391.

Sharov, A. A., A. M. Liebhold, and F. W. Ravlin. 1995. Prediction of gypsy moth (Lepidoptera: Lymantriidae) mating success from pheromone trap counts. Environmental Entomology 24: $1239-1244$.

Shigesada, N., and K. Kawasaki. 1997. Biological invasions: Theory and Practice. Oxford Series in Ecology and Evolution, Oxford University Press, Oxford.

South, A. B., and R. E. Kenward. 2001. Mate finding, dispersal distances and population growth in invading species: a spatially explicit model. Oikos 95: 53-58.

Stephens, P. A., and W. J. Sutherland. 1999. Consequences of the Allee effect for behavior, ecology and conservation. Trends in Ecology \& Evolution 14: 401-405.

Taylor, C. M., and A. Hastings. 2005. Allee effects in biological invasions. Ecology Letters 8: 895908.

Taylor, C. M., H. G. Davis, J. C. Civille, F. S. Grevstad, and A. Hastings. 2004. Consequences of an Allee effect on the invasion of a Pacific estuary by Spartina alterniflora. Ecology 85: 32543266.

Tobin, P. C., S. L. Whitmire, D. M. Johnson, O. N. Bjørnstad, and A. M. Liebhold. 2007. Invasion speed is affected by geographic variation in the strength of Allee effects. Ecology Letters 10: $36-43$.

Tobin, P. C., C. Robinet, D. M. Johnson, S. L. Whitmire, O. N. Bjørnstad, and A. M. Liebhold. 2009. The role of Allee effects in gypsy moth, Lymantria dispar (L.), invasions. Population Ecology (in press).

Wagner, D. L., and J. K. Liebherr. 1992. Flightlessness insects. Trends in Ecology \& Evolution 7: 216-220. 
Wallner, W. E. 1996. Invasion of the tree snatchers. The Asian gypsy moth’s entrance into North America shows that exotic-pest invasions can happen in unexpected ways. American Nurseryman March 15, 1996: 28-30.

Wells, H., E. G. Sttrauss, A. M. Rutter, and P. H. Wells. 1998. Mate location, population growth and species extinction. Biological Conservation 86: 317-324.

Whitmire, S. L., and P. C. Tobin. 2006. Persistence of invading gypsy moth populations in the United States. Oecologia 147: 230-237.

Williamson, M., and A. Fitter. 1996. The varying success of invaders. Ecology 77: 1661-1666.

Williamson, M. 2006. Explaining and predicting the success of invading species at different stages of invasion. Biological Invasions 8: 1561-1568.

With, K. A. 2002. The landscape ecology of invasive spread. Conservation Biology 16: 1192-1203.

Zera, A. J., and R. F. Denno. 1997. Physiology and ecology of dispersal polymorphism in insects. Annual Review of Entomology 42: 207-230. 


\section{FIGURE LEGENDS}

Figure 1. Flow diagram of the model. Thin lines represent processes of the model developed by Robinet et al. (2008), and thick lines new processes considered in this paper. See Table 2 in Robinet et al. (2008) for a detailed list of variables and default values.

Figure 2. Combined effects of dispersal ability and number of eggs initially introduced on the 2-year population growth rate. (a) Mean growth rate for $D=0$ to 2 by $0.1 \mathrm{~km}^{2} /$ generation, and $N_{\text {egg }}=100$ to 3000 by 100 . The thick line represents the critical growth rate $r=1$. (b) lntransformed growth rate as a function of the diffusion coefficient for adult female dispersal $(D=0$ to 2 by 0.1 ) given $N_{\text {egg }}=500,1000$, and 3000. (c) Population growth rate as a function of the number of eggs initially introduced ( $N_{\text {egg }}=100$ to 1500 by 100), for non-dispersing populations ( $D$ $=0)$, and long-distance dispersing populations $(D=1)$. The dotted line indicates the threshold growth rate $r=1$. Thick lines represent the mean and thin lines represent the $95 \%$ confidence interval of growth rates. We considered a fecundity $f=500$ eggs, and made 500 replicate simulations.

Figure 3. Combined effects of dispersal ability and number of eggs initially introduced on the spread distance. This distance was calculated as the square root of the area of all occupied $1 \mathrm{~km}$ $\times 1 \mathrm{~km}$ cells. (a) Mean spread distance $d$ for $D=0$ to 2 by $0.1 \mathrm{~km}^{2} /$ generation, and $N_{\text {egg }}=100$ to 3000 by 100 . (b) Mean spread distance as a function of the diffusion coefficient ( $D=0$ to 2 by 0.1 ) given $N_{\text {egg }}=500,1000$, and 3000. (c) Spread distance as a function of the number of eggs initially introduced ( $N_{\text {egg }}=100$ to 3000 by 100$)$, for non-dispersing populations $(D=0)$ and long-distance dispersing populations $(D=1)$. Thick lines represent the mean and thin lines represent the 95\% confidence interval of spread distances. We considered a fecundity $f=500$ eggs, and made 500 replicate simulations. 
Figure 1.

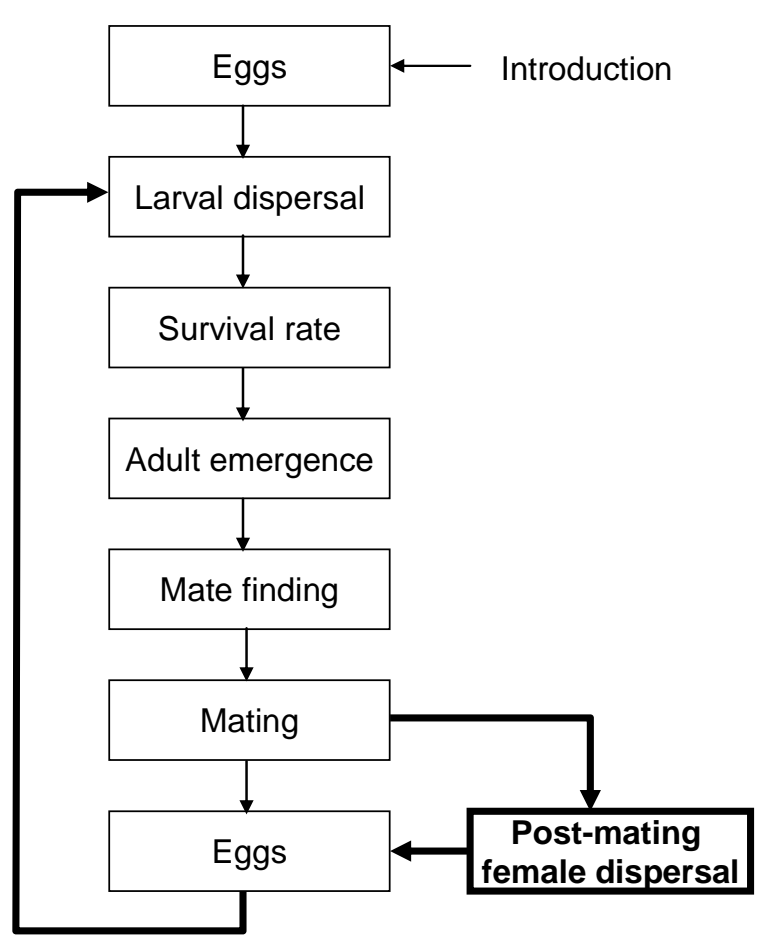


Figure 2.
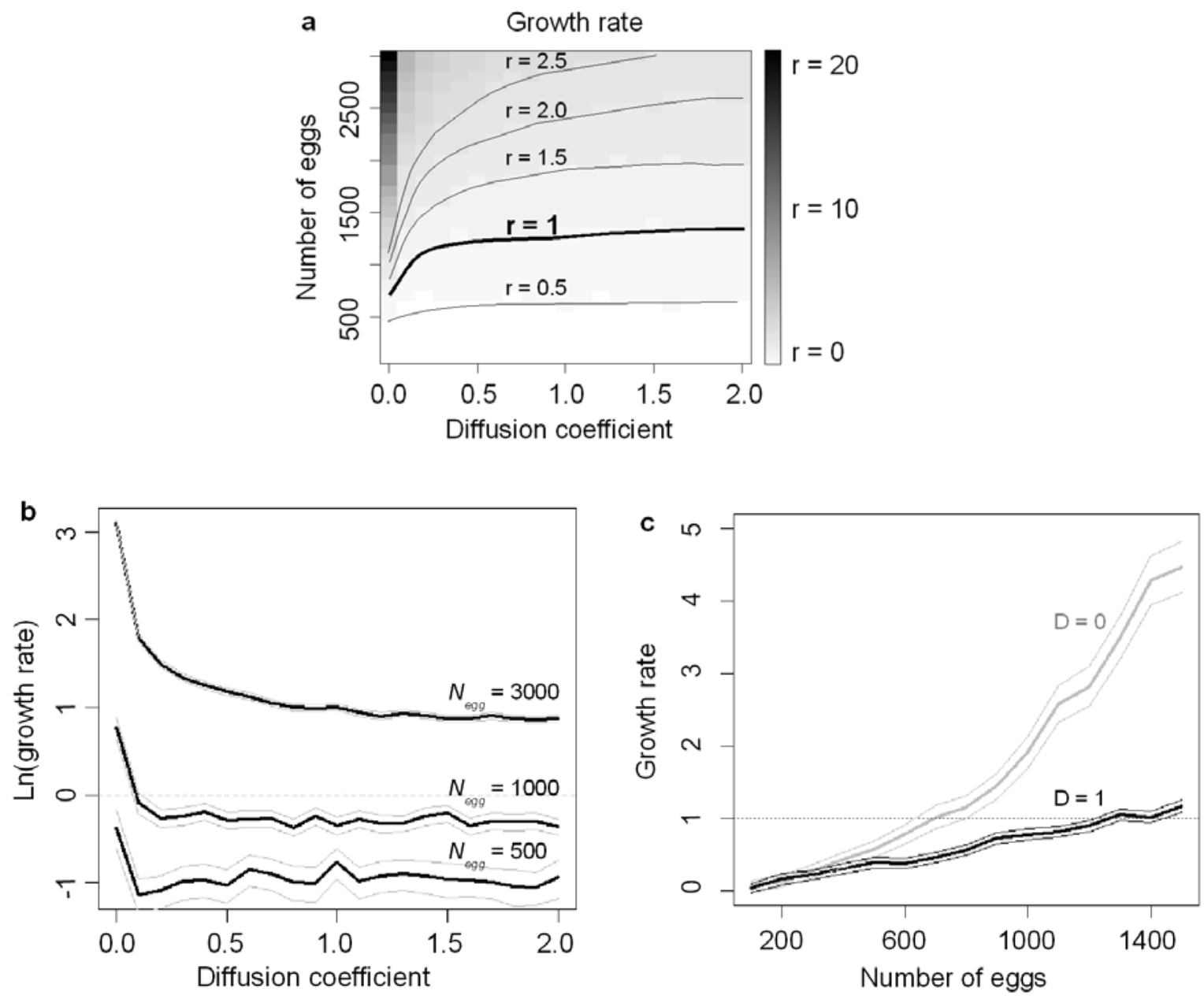
Figure 3.
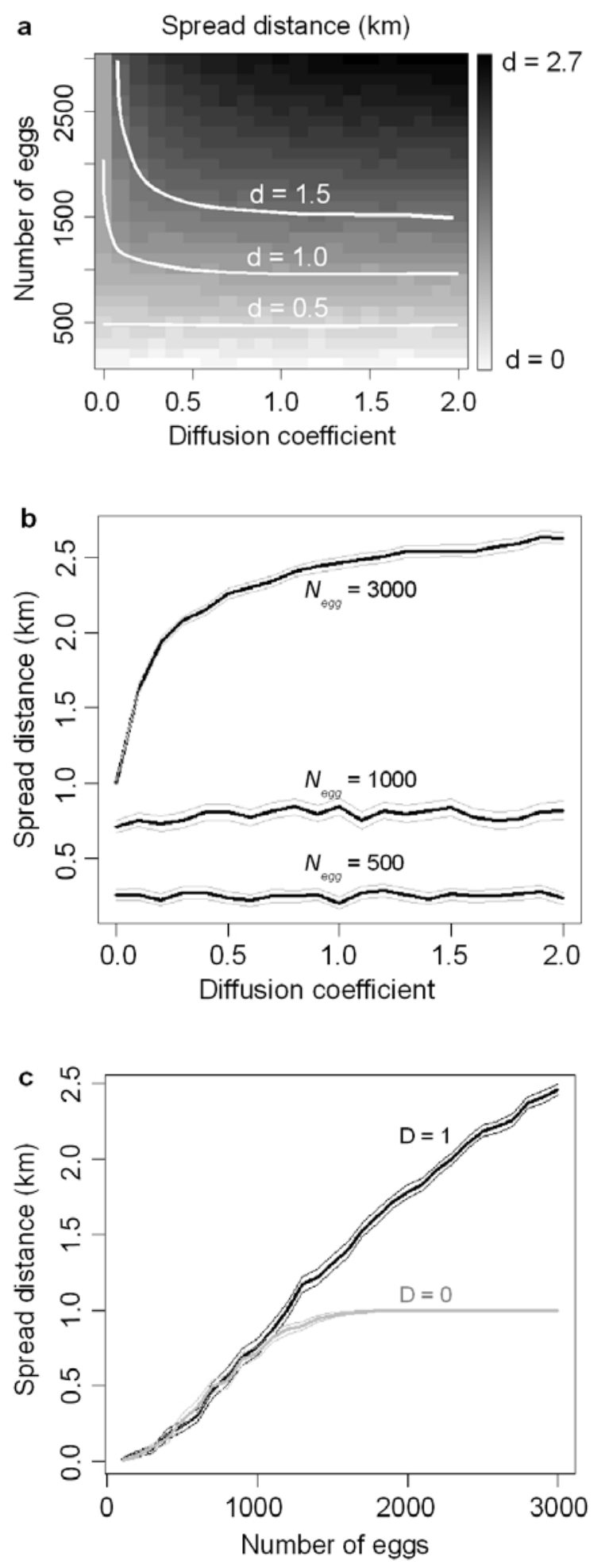